\title{
Tailoring therapeutic strategies for treating posttraumatic stress disorder symptom clusters
}

This article was published in the following Dove Press journal:

Neuropsychiatric Disease and Treatment

23 August 2010

Number of times this article has been viewed

\author{
Seth D Norrholm ${ }^{1,2}$ \\ Tanja Jovanovic ${ }^{2}$ \\ 'Atlanta VA Medical Center, \\ Mental Health Service Line, \\ Decatur, GA, USA; ${ }^{2}$ Department of \\ Psychiatry and Behavioral Sciences, \\ Emory University School of \\ Medicine, Atlanta, GA, USA
}

\begin{abstract}
According to the Diagnostic and Statistical Manual of Mental Disorders, 4th edition, posttraumatic stress disorder (PTSD) is characterized by three major symptom clusters following an event that elicited fear, helplessness, or horror. This review will examine each symptom cluster of PTSD separately, giving case study examples of patients who exhibit a preponderance of a given symptom domain. We use a translational approach in describing the underlying neurobiology that is relevant to particular symptoms and treatment options, thus showing how clinical practice can benefit from current research. By focusing on symptom clusters, we provide a more specific view of individual patient's clinical presentations, in order to better address treatment needs. Finally, the review will also address potential genetic approaches to treatment as another form of individualized treatment.
\end{abstract}

Keywords: psychophysiology, pharmacotherapy, exposure therapy, pharmacogenetics; posttraumatic stress disorder, symptom clusters

\section{Introduction}

Posttraumatic stress disorder (PTSD) is considered the fourth most common psychiatric diagnosis, affecting $10 \%$ of all men and $18 \%$ of all women. ${ }^{1}$ In the aftermath of September 11th, 2001, in New York City, almost 57.8\% of the population experienced at least one symptom of PTSD, ${ }^{2}$ whereas $11.2 \%$ developed full criteria for the disorder. ${ }^{3}$ The increased incidence of combat zones worldwide and the continued prevalence of violence in large urban centers in the United States enhance the likelihood of exposure to traumatizing events during one's lifetime. Combat-related PTSD is especially pervasive: according to the National Vietnam Veterans Readjustment Study in 1988, 30.8\% of male and $26.9 \%$ of female veterans suffered from PTSD at some point during their lives after combat. ${ }^{4}$ Many Vietnam theater veterans with PTSD have endured persistent social, medical, and psychological problems for close to 3 decades. Approximately two-thirds of the Vietnam veteran population has been divorced with an estimated one-fourth experiencing serious parenting problems. In addition to difficulties within family relationships, approximately $75 \%$ of Vietnam veterans with PTSD have abused or become dependent on alcohol in their lifetime, and an estimated $36 \%$ have been repeatedly arrested or incarcerated. ${ }^{4}$ In the current geopolitical climate, combat-related PTSD is a serious and global illness. The conflicts in Iraq and Afghanistan, although markedly different in many respects compared with the Vietnam theater of conflict (eg, improvised explosive devices, suicide bombings, urban warfare), have produced a large number of new PTSD cases, with early reports documenting a rate of $12.9 \%$ soldiers meeting strict criteria for PTSD and $18 \%$ meeting more broadly defined criteria. ${ }^{5}$ 
Of course, PTSD is not limited to veterans who experience combat trauma. An increasing number of studies ${ }^{6-8}$ indicate that African Americans living in urban environments with low income are at, especially, high risk for both exposure to traumatic events and PTSD. For example, a recent study of 617 primary care patients (96\% of whom were African Americans) found a $65 \%$ rate of lifetime trauma exposure and a 33\% rate of PTSD. ${ }^{9}$ In such samples, exposure to trauma may begin early in life; studies of children and young adults from similar samples suggest that initial trauma exposure during childhood or adolescence is common. ${ }^{10}$ Studies of PTSD in civilian population have found a wide range of traumatic events that lead to the development of the disorder, such as motor vehicle accidents, ${ }^{11}$ sexual assault, ${ }^{12}$ including intimate-partner violence, ${ }^{13}$ and natural disasters, such as hurricanes. ${ }^{14}$ In the aftermath of the recent earthquake in Haiti resulting in large-scale devastation and loss of life, we can expect a number of new cases of the disorder. ${ }^{15}$

According to the Diagnostic and Statistical Manual of Mental Disorders, 4th edition(DSM-IV), ${ }^{16}$ PTSD is characterized by three major symptom clusters following an event that elicited fear, helplessness, or horror (shown in Figure 1). The first category includes symptoms of traumatic events reexperiencing, such as intrusive thoughts, nightmares, and flashbacks, and phenomena that are often induced by reminders of the event. The second cluster is associated with avoidance of stimuli associated with the traumatic event, such as loss of interest in social interactions and detachment. The final category describes trauma-induced physiological alterations, such as increased startle and hyperarousal including tachycardia, elevated perspiration, and shortness of breath. A new edition of the DSM, scheduled for publication in May 2013, will update the diagnostic criteria for PTSD. The proposed changes for DSM-5 include reorganizing the individual symptoms into four broad categories; most notably, the current proposal is to separate avoidance symptoms and emotional numbing symptoms into different clusters (see http://www.dsm5.org/ for proposed changes). However, the core symptoms will still remain in the diagnostic criteria for the disorder, thus the emphasis on individual symptoms rather than on the disorder as a whole is very timely. In fact, a recent paper by Shea and colleagues ${ }^{17}$ highlight the importance of

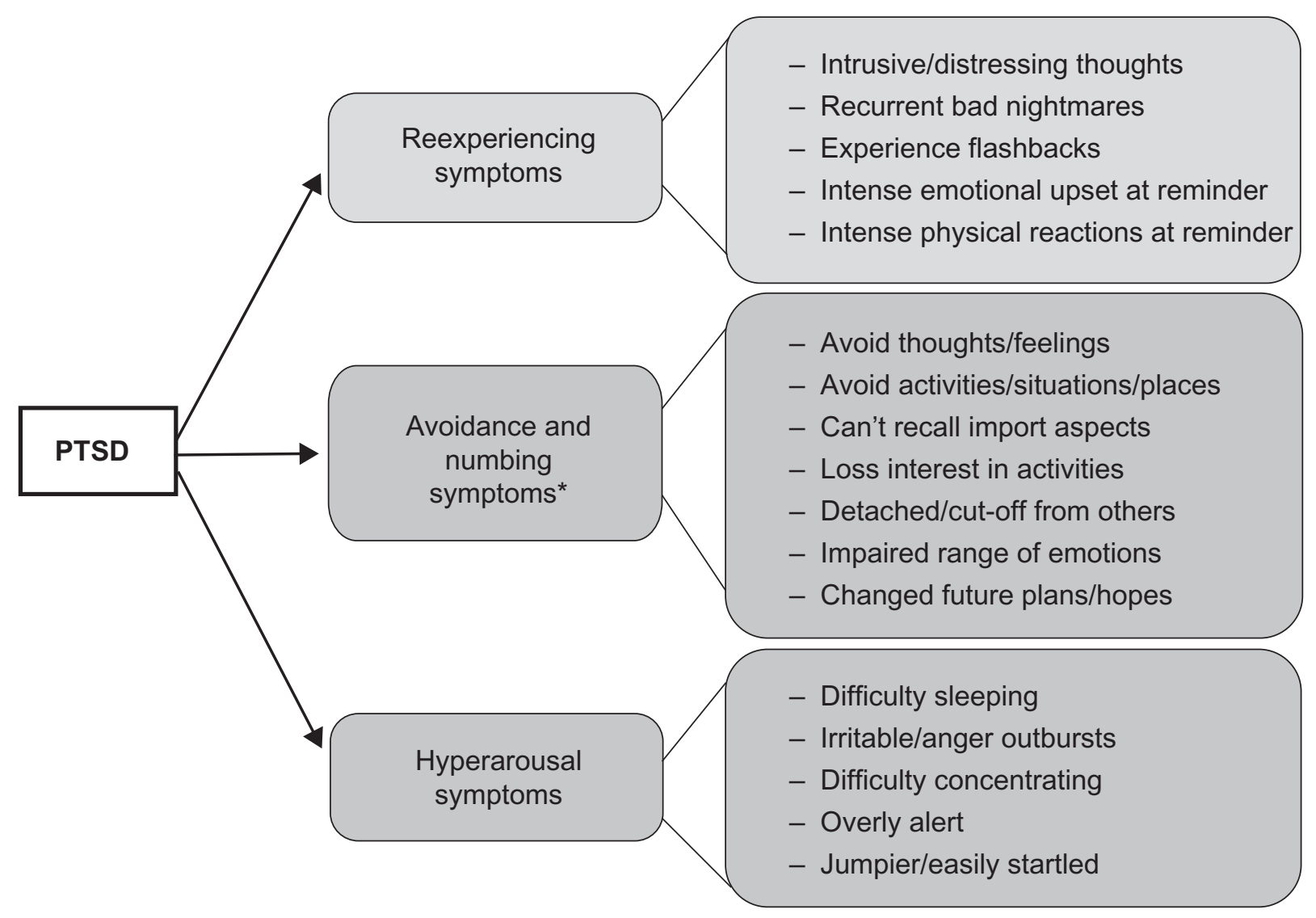

Figure I Diagram of PTSD symptoms broken down by the 3 diagnostic symptom clusters according to DSM-IV. Note: *Proposed changes for DSM-V include separating avoidance and numbing symptoms into different clusters. 
treating patients who exhibit some but not all of the requisite PTSD symptoms across clusters for a full PTSD diagnosis (subsyndromal PTSD).

The heterogeneity of PTSD, by nature, implicates the involvement of several divergent neural systems in the underlying neurobiology of PTSD symptomatology; ${ }^{18}$ In addition, individual differences in one's neurobiological makeup may also contribute to the variability observed in patient presentations following trauma exposure..$^{19}$ Increasing our understanding of these neurobiological underpinnings can (1) greatly enhance our knowledge of the disease itself, (2) inform the development of novel treatments for PTSD symptom clusters, and (3) improve patient outcomes and prevent symptom relapse.

The heterogeneous expression of PTSD symptomatology may be strongly influenced by an individual's autonomic response following trauma exposure; the output of the autonomic nervous system can be indexed noninvasively via psychophysiological assessments of several peripheral targets, such as heart rate, blood pressure, skin conductance, respiration rate, muscle contractions, and body temperature. Thus, these measurements provide a potential "objective" manner to assess PTSD symptom expression and severity. Technological advances in the last decade have made such measurements possible using relatively simple methods at a reasonable cost and without extensive training in psychophysiology. In other words, physiological indices can be easily obtained in most clinical settings and may prove beneficial in the diagnosis and treatment evaluation of PTSD.

Several theorists ${ }^{20-22}$ have proposed that fear conditioning processes are involved in the etiology and maintenance of PTSD. As mentioned earlier, the DSM-IV diagnosis of PTSD requires exposure to a traumatic event and a cluster of symptoms associated with that event (eg, psychological and physiological reactions to trauma reminders and avoidance of such reminders). This model suggests that through Pavlovian conditioning, neutral stimuli (conditioned stimuli [CSs]) that are temporally or spatially proximal to an aversive stimulus (unconditioned stimulus [US]) become associated and can elicit a conditioned fear response in the absence of the US. Thus, neutral stimuli (the CSs) present at the time of the trauma (the US) acquire the ability to elicit a conditioned fear reaction that can be triggered when the person subsequently encounters these or similar stimuli during the course of normal life. Consistent with this hypothesis, emotional and physiological reactivity to stimuli resembling the original traumatic event (even years after the event's occurrence) is a prominent characteristic of PTSD and has been reliably replicated in the laboratory. ${ }^{23,24}$ Cognitive and behavioral avoidance strategies are further hypothesized to develop in an attempt to avoid or escape these distressing conditioned emotional reactions. One of the earliest theories proposed to explain avoidance behavior is Mowrer's 2-factor theory, ${ }^{25,26}$ which posits that escape of a fear-conditioned stimulus negatively reinforces avoidance behavior, thereby maintaining fear responses. Applied to PTSD, this theory suggests that avoidance of reminders of the trauma can maintain the disorder by preventing extinction of the original fear associations. ${ }^{27}$ Finally, overgeneralization of trauma-related stimuli or situations (ie, an impaired ability to discriminate between danger and safety cues) $)^{28,29}$ can lead to hypervigilance and exaggerated startle responses that are part of the hyperarousal symptom cluster. Data from our laboratory have shown that PTSD patients with high hyperarousal symptoms have the greatest difficulty in inhibiting fear responses to safety cues. ${ }^{29}$

Conceptualizing PTSD within the framework of fear conditioning affords the use of laboratory paradigms, such as fear inhibition and fear extinction, to better understand altered fear processing and to develop better treatments for this dysregulation. As mentioned earlier, most trauma victims show fear and related reactions after a traumatic event, but these effects diminish over time in most traumatized individuals. We believe this reflects an intact ability to extinguish learned fear and that the development of chronic PTSD in traumatized individuals who do not recover represents a failure of fear extinction. The inability to extinguish conditioned fear may be due to a complex gene-environment interaction between one's individual predisposition(s) and environmental factors, such as early life stress and the frequency, degree, and intensity of traumatic event(s). Several psychological models of PTSD have been proposed in the literature, including information-processing theory and emotional-processing theory (see Brewin and Holmes $^{30}$ ), that provides cognition-based theories of the disorder. ${ }^{3}$ However, fear conditioning offers a unique framework for translational studies, given that it can be modeled in animal experiments. Given the richness of the animal literature, the neural underpinnings of fear conditioning are well understood, and PTSD research can capitalize on these findings. ${ }^{32}$

The neurobiological model of fear dysregulation in PTSD suggests that responses to fearful stimuli can be so powerful that the cortical inputs are unable to inhibit amygdala activity, as indicated by evidence of decreased prefrontal cortex (PFC) activity ${ }^{33}$ and increased amygdala activity $^{34}$ during presentations of traumatic imagery or fear-evoking stimuli. Neuroimaging data collected during the last decade demonstrate that PTSD patients appear to 
have greater amygdala activation compared with controls (for a recent review, see Liberzon and Sripada ${ }^{35}$ ).Positron emission tomography (PET) studies using combat scripts ${ }^{36}$ and images ${ }^{33,37}$ and single-photon emission computed tomography (SPECT) studies comparing responses to combat sounds to white noise ${ }^{34}$ found greater levels of amygdala activation in PTSD patients. Furthermore, recent functional magnetic resonance imaging (fMRI) studies have found that trauma-relevant words increase amygdala activation. ${ }^{38}$ This increased fear response extends beyond trauma-specific imagery: fearful faces also activate the amygdala in PTSD patients more than in controls. ${ }^{39,40}$ Exaggerated fear responses observed in PTSD may be due to a weakened inhibitory control of the amygdala by the medial PFC (mPFC). PET studies of patients with PTSD show decreased anterior cingulate cortex (ACC, part of the PFC) activation to the emotional Stroop using fear-evoking words, such as "rape"; 41 however, PTSD patients have normal mPFC activation to nonemotional interference tasks. ${ }^{41,42}$ Weakened mPFC control of the amygdala may be a risk factor for psychopathology: a recent study of children with depressed parents found a lack of ACC activation to the emotional Stroop, using both fearrelevant words depicting physical threat and social threat. ${ }^{43}$

The amygdala is an integral part of the neural circuit that controls fear responses and the peripheral targets of fear responses, such as those that can be measured using psychophysiological recordings. ${ }^{44}$ Figure 2 shows the neurobiological outputs that would be observed during dangerous conditions, such as those evoking "flight or fight" responses.
The central nervous system responds with activation of the amygdala, which in turn activates several loci of the peripheral nervous system, specifically the sympathetic nervous system via the lateral hypothalamus that increases sweat gland activity, measured by skin conductance levels (SCLs), and the parasympathetic nervous system (PNS) via the dorsal nucleus of the vagus increasing high-frequency heart-rate variability, measured by respiratory sinus arrhythmia (RSA). In addition, the amygdala directly stimulates the pons, thus resulting in fear-potentiated startle responses. Therefore, arousal would be marked by increased SCL, decreased RSA, and heightened startle responses. On the other hand, during safe conditions, the mPFC suppresses amygdala activity via inhibitory connections between the two regions; a PTSD patient with a dysregulated fear system might show hyperarousal by displaying this physiological profile in less dangerous or safe situations. Another system that modulates arousal is the PNS, which operates through two vagal systems that originate in different brainstem nuclei, ${ }^{45}$ the myelinated vagus via the nucleus ambiguous is involved in resting states, reducing arousal during nonthreatening situations. However, in some individuals, the PNS can also be activated via the dorsal nucleus of the vagus, which is a more primitive, unmyelinated vagal output; during extreme fear-evoking situations, this output can override the sympathetic activation via the ventrolateral periaqueductal gray. ${ }^{46}$ This type of response has been observed in dissociation ${ }^{45}$ and is associated with a decrease in $\mathrm{SCL}^{47}$ and an increase in RSA. Thus, PTSD patients exhibiting a more dissociative type symptomatology

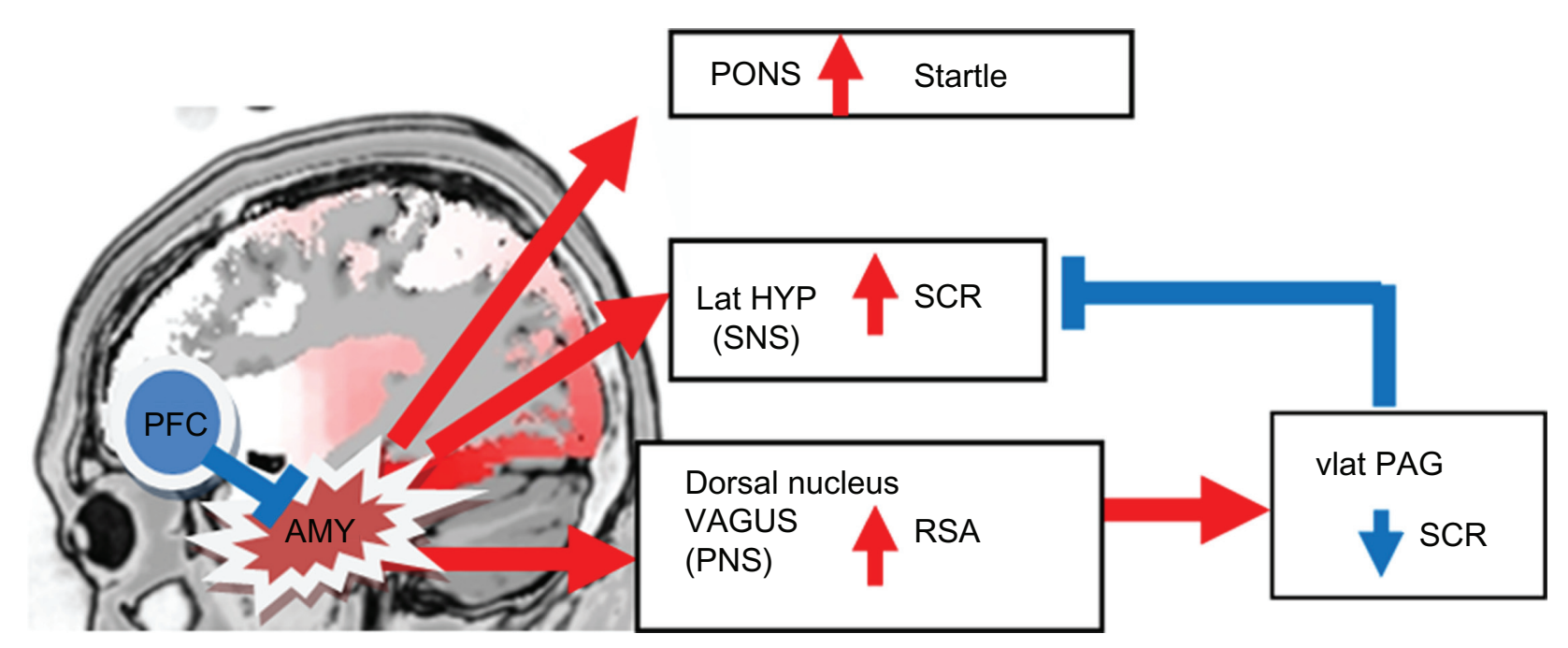

Figure 2 Diagram of the neurobiology of fear responses. The amygdala is not drawn to scale.

Abbreviations: PFC, prefrontal cortex; AMY, amygdala; lat HYP, lateral hypothalamus; SNS, sympathetic nervous system; PNS, parasympathetic nervous system; SCR, skin conductance response; RSA, respiratory sinus arrhythmia; vlat PAG, ventrolateral periaqueductal gray. 
may have a different psychophysiological profile than those with greater hyperarousal symptoms.

Fear extinction involves a conditioning session in which a cue that was previously associated with danger is presented repeatedly without the US so that it no longer evokes the fear response. In the fear conditioning model of PTSD, extinction serves as a model for exposure-based therapy. Therefore, understanding the neurobiological bases of extinction is also of great importance to optimizing treatment. Neuroimaging studies using fear conditioning paradigms show that fear acquisition and extinction of fear also activate the PFC, specifically the ventromedial PFC (vmPFC). ${ }^{48}$ Similar studies with PTSD patients have found decreased vmPFC activation during fear extinction compared with traumatized controls. ${ }^{49}$ Considerable neurochemical evidence also implicates the amygdala in the formation of extinction memories.

Several studies from the Davis lab have shown the role of $N$-methyl-D-aspartate (NMDA) receptors, as well as the MAP kinase second-messenger cascade in extinction memory. ${ }^{50-52}$ Falls and colleagues ${ }^{51}$ first showed that NMDA antagonists dose-dependently block the acquisition of extinction learning. Others have confirmed that intra-amygdalar antagonists ${ }^{53}$ impair extinction learning. D-cycloserine (DCS), an NMDA partial agonist, facilitates extinction learning when infused bilaterally within the basolateral amygdala prior to extinction. ${ }^{54}$ Notably, the intra-amygdala effect was as robust as the systemic drug effect, suggesting that the amygdala is the primary site of action.

This review will address each symptom cluster of PTSD separately while providing case studies from Operation Iraqi Freedom/Operation Enduring Freedom (OIF/OEF) combat veterans with PTSD, who exhibit hallmark signs and symptoms within a given symptom domain. These clinical "snapshots" serve as real-life illustrations of the symptom presentations by patients and do not imply that those are the full extent of the patient's symptom profile. Next, the potential neurobiological underpinnings of each symptom domain will then be discussed and optimal treatment strategies explored. The use of pharmacotherapies for the treatment of PTSD will be discussed in terms of drugs that have proven effective at treating specific symptom clusters. However, for a full review of pharmacotherapy for PTSD, there are several recent reviews currently available. ${ }^{55-58}$ A primary objective of this review is to highlight the need for more customized treatment regimens given (a) individual patient variability across the PTSD syndrome spectrum and (b) the increasing emergence of subsyndromal PTSD cases in which one or more symptom clusters (but not enough for a full PTSD diagnosis) are endorsed and cause significant distress and impairment. ${ }^{17}$

\section{Treatment of full diagnostic PTSD}

The current dogma related to psychiatric treatment of PTSD addresses the disorder as a whole and not with respect to individual symptom clusters. In the following sections, we will discuss treatment options that are most promising in targeting specific symptoms that may be applied to future therapeutic strategies. Existing treatments include forms of psychotherapy and psychopharmacology, treatments that are typically applied without consideration for individual symptom profiles.

The first-line, nonpharmacological treatment approach for PTSD has traditionally been psychological treatments, including psychoeducation, individual psychotherapy, and group psychotherapy. ${ }^{59}$ Psychoeducation, which is not intended to be a stand-alone intervention, is designed to provide a patient with information regarding the nature and course of PTSD to a traumatized individual presenting with PTSD-related symptoms. ${ }^{59}$ Individual psychotherapy is aimed at specific PTSD symptom clusters and includes cognitive behavioral therapy (CBT) techniques, such as prolonged exposure (PE), ${ }^{60-62}$ and cognitive processing therapy (CPT).

PE therapy is widely regarded as an effective form of individual psychotherapy for PTSD. ${ }^{63-66}$ As described by Friedman, ${ }^{59}$ exposure to a traumatic event (Criterion $A_{1}$ ) can produce a robust emotional response (Criterion $\mathrm{A}_{2}$ ), and this association can lead to PTSD avoidance symptoms through learning and conditioning paradigms. Avoidant behaviors become more frequent as a means of reducing the strong emotional responses to trauma-related stimuli. The primary purpose of CBT (including PE) is to deconstruct the PTSD-related aberrant thinking patterns that underlie avoidance. Effective PE techniques include imaginal and in vivo exposure to stimuli that are related to the traumatic event and a patient's memories of this event. ${ }^{67}$ Imaginal exposure therapy requires the patient to narrate their traumatic experience during weekly sessions that continue for 8-10 weeks, with patient's distress level often assessed with the Subjective Units of Distress Scale (SUDS). ${ }^{65}$ An important step in imaginal exposure is for the patient to face contexts directly related to their traumatic experience during in vivo contact. ${ }^{60}$

The use of PE therapy has reportedly been limited in military populations because of a perceived stigma within military peer groups and the military leadership hierarchy. ${ }^{5}$ Imaginal exposure therapy also requires intensive emotional 
engagement in order to retrieve and activate fear memories. PTSD patients are often resistant to and avoidant of this level of engagement. ${ }^{68}$ For this reason, virtual reality (VR) can be presented as an attractive alternative to "stigmatized" talk therapy and imaginal exposure therapy, as well as an innovative means to reach avoidant PTSD patients. The use of immersive visual, tactile, and olfactory cues in a VR environment can reliably evoke fearful memories. VR has been successfully used for treatment of PTSD in 9/11 World Trade Center survivors ${ }^{69}$ and Vietnam veterans. ${ }^{62}$ Recent studies have demonstrated the validity of using $\mathrm{VR}^{70}$ and its success in treating combat veterans from OIF. ${ }^{71}$ Reger and colleagues $^{70}$ presented 93 returning OIF veterans without PTSD with VR environments depicting an Iraqi cityscape and a desert convoy, two environments that are often experienced by military personnel serving tours in Iraq. In the Reger study, combat-exposed personnel rated both environments as realistic representations of the actual scenarios into which they were deployed. This was a necessary first step in the dissemi- nation and optimization of VR exposure therapies for treating cases of combat PTSD related to this theater of conflict. Early case reports have indicated significant symptom amelioration with a virtual Iraq treatment environment. ${ }^{71}$ It is important to note that the recent cohort of returning veterans from OIF/ OEF may seek technological innovations such as VR for their PE treatment given that they were raised during an era in which video gaming is a popular pastime (see Figure 3 ).

CPT enables PTSD patients to focus on the cognitive and emotional aspects of their traumatic event through the written narratives detailing their experience. ${ }^{72}$ This is believed to help the patient better process and understand the raw emotions that have been altered by their own misinterpretations of the traumatic experience. ${ }^{65}$ Based on CPT theory, the ability to process trauma-related natural and raw emotions, such as fear and melancholy, is blocked by patient-generated negative belief systems. This blockade is often the result of a preoccupation with overpowering emotions, including shame and guilt. CPT is aimed at helping the patient confront altered traumatic

\section{\begin{tabular}{c} 
Full PTSD diagnosis or \\
clinically significant PTSD symptoms (subsyndromal) \\
\hline
\end{tabular}}

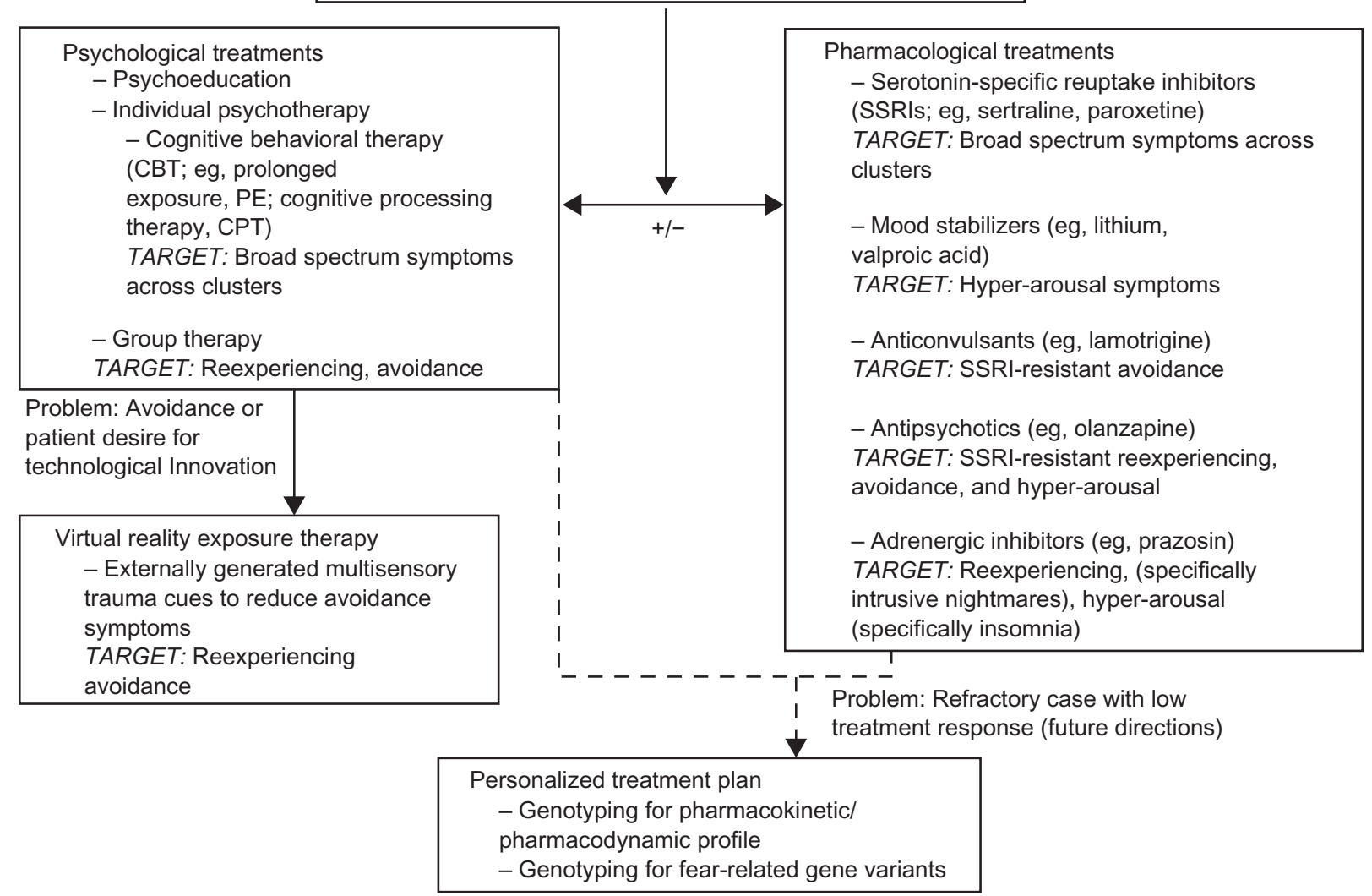

Figure 3 PTSD treatment options spanning psychological and pharmacological measures. Upon full diagnosis of PTSD or clinically significant impairment on one or more PTSD symptom clusters without full diagnosis (subsyndromal), clinicians will typically begin a course of psychological treatments with or without concurrent pharmacological treatment. Pharmacological treatment is indicated in situations in which (I) the patient is receiving drug treatment, (2) there is a high degree of comorbid symptomatology (eg, major depression, panic disorder), and (3) full-scale CBT treatment is currently unavailable. ${ }^{59}$

Note: + -, indicates in combination or as single-line treatment regimens; dashed line, indicates a future direction for PTSD patient care. 
memories while modifying negative belief systems (eg, "I am not powerless to face the dangers in my environment."). CPT has shown significant effectiveness in treating PTSD symptoms across clusters, equivalent to PE. ${ }^{73}$

At this point, it is important to note that many of the pharmacological studies that have informed drug treatments for PTSD have significant limitations including small sample size and reduced power, a lack of double-blinding and randomization, and inconsistent dosing regimens. ${ }^{74}$ In fact, a recent report of the Institute of Medicine of the National Academies concluded that there was insufficient evidence to support efficacy of pharmacological treatment for PTSD. ${ }^{63}$ In spite of these limitations, several classes of drugs have been used in the treatment of symptoms of this disorder. Berger and colleagues ${ }^{56}$ recently reviewed the psychopharmacotherapies for treating PTSD that have evolved over the past two decades. Multiple drug classes, including antipsychotics, anticonvulsants, adrenergic-inhibitors, opioids, and benzodiazepines, were rated according to the empirical support behind their therapeutic value for treating PTSD. Berger and colleagues, using US Department of Health and Human Services Guidelines (1993), categorized the drug classes as follows: (1) level A, multiple double-blind, placebo-controlled trials with positive results (with level B criterion met); (2) level $\mathrm{B}$, at least 1 double-blind, placebo-controlled trial with positive result (and level C criterion met); (3) level C, anecdotal reports, case studies, and open trials with positive results and/or expert support; and (4) level D, few case reports with positive results and no expert support. ${ }^{75}$ Berger and colleagues found no drug classes meeting criteria for level A of evidence for use as a pharmacotherapy for PTSD. Of the remaining categorizations, five of the drugs studied by the Berger group were listed at level B, 7 at Level C, and 13 at level D. The most promising agents, determined to be level $\mathrm{B}$ by Berger and others, were risperidone and olanzapine (antipsychotics), valproic acid and lamotrigine (anticonvulsants), and prazosin (adrenergic inhibitor). The use of these drugs for treating specific PTSD symptom clusters will be discussed further below.

\section{Reexperiencing (intrusive) symptoms \\ Clinical snapshots}

A 28-year-old male combat veteran from OIF has nightmares 6-7 times a week about combat experiences and thinks he is dying; he wakes up sweaty, upset, and confused, with hands locked. He experiences severe flashbacks 2-3 times a week and has daily intrusive thoughts. The patient reports panic attacks once a week and states, "Everywhere I look, I see Iraq".

A 22-year-old male combat veteran reports militaryrelated dream content 1-2 times in the past week, and he also endorses waking up with "cold sweats". He also states that when he lived with his wife, she used to comment that he thrashed around in his sleep 1-2 times per week. Patient endorsed having flashbacks twice per month, which are triggered when he encounters trash on the side of the road. Patient states, "The thing that I think about the most are the people that I knew that didn't come back".

A 29-year-old female veteran reports symptoms of PTSD related to childhood sexual abuse. She reports having intrusive thoughts about the experience, particularly when reminded by external stimuli (eg, a news story about molestation), and that these thoughts are distressing to her. She reports having occasional nightmares about her childhood sexual trauma.

\section{Neurobiological underpinnings}

PTSD symptoms falling into this cluster, which is focused on intrusive thoughts and reexperiencing the traumatic event, are among the most diagnostically "classic" symptoms of PTSD, in that they are most closely linked to the traumatic event. This does not, however, imply that these symptoms have the greatest impact on patient reports of distress and impairment; ${ }^{17}$ many patients report that avoidance and numbing symptoms cause the greatest degree of life impact. ${ }^{76,77}$ These symptoms will be discussed further below. Reexperiencing symptoms characteristically contain an exaggerated fear component. As described in the introduction, neuroimaging studies using trauma-relevant stimuli and psychophysiological reactivity tests using script-driven imagery have examined the biological bases of these symptoms. PET and fMRI studies using trauma reminders have shown limbic hyperactivity in the amygdala. ${ }^{35}$ More peripheral measures of fear responding, such as skin conductance, heart-rate variability, and facial muscle contractions have also been measured during script-driven imagery studies. In a typical scriptdriven imagery study, the participant describes an actual traumatic event from their combat experience. This event is then edited into a 30-second script that is read and recorded by the experimenter. ${ }^{24}$ The script is then played back to the participant while recording psychophysiological data that is then compared with physiological recordings during a resting period. This method has been used with many different PTSD populations: World War II veterans, ${ }^{78}$ Korean War veterans, ${ }^{78}$ Vietnam War veterans, ${ }^{79}$ Israeli War veterans, ${ }^{80}$ and Vietnam War combat nurses, ${ }^{81}$ in addition to sexual assault 
victims. ${ }^{82}$ Among the trauma survivors observed across these studies, PTSD patients exhibited stronger heart rate and skin conductance responses to scripts than non-PTSD trauma survivors.

In 1998, Keane and colleagues ${ }^{83}$ published the largest study to date examining the utility of psychophysiological measures in diagnosing PTSD. The study was a multisite Department of Veterans Affairs Cooperative Study investigating 1,461 Vietnam War veterans using script-driven imagery and standardized combat images with psychophysiological recordings. Although their study did not find a perfect correlation between interview-based PTSD diagnosis and psychophysiological reactivity, they did conclude that psychophysiological data provides useful and objective assessments of PTSD symptoms. It should be noted that the study could not conclude that psychophysiological assessments would provide a clear diagnostic tool; however, the group differences speak to the underlying neurobiology of the disorder, as indexed by different physiological biomarkers.

Although exaggerated startle responses, in general, are characterized as hyperarousal symptoms, fear-potentiated startle, given its dependence on the amygdala, ${ }^{84}$ may be better described as a reexperiencing symptom. Using fear-potentiated startle methods with a population of Vietnam veterans with PTSD, our group found that higher current symptoms were associated with greater fear expression and impaired inhibition of fear. ${ }^{28}$ Data from our civilian PTSD cohorts recruited from a highly traumatized, low-income, inner-city population indicate that fear-potentiated startle is associated with intrusions and emotional and physical responses to trauma reminders (see Table 1). Impaired inhibition of fear-potentiated startle may be a specific biomarker for PTSD; ${ }^{29}$ which may be a vulnerability factor for the disorder or an acquired trait. Prospective studies using fear extinction prior to traumatization in civilian populations at high risk for trauma exposure have shown an association of impaired inhibition and PTSD symptoms after trauma. ${ }^{85,86}$
Impaired fear inhibition to trauma stimuli is one of the common neuroimaging findings in PTSD. ${ }^{35}$ Recent studies have explored neural activation with regard to PTSD symptom clusters and have found distinct neurobiological "subtypes." 18

In our urban trauma sample of 169 participants, reexperiencing symptoms were positively correlated with RSA measured with spectral analysis of high-frequency heart-rate variability during fear condition. More specifically, flashback symptoms and physiological reactivity were positively associated with this measure of PNS control (Table 1). It is possible that reexperiencing symptoms are associated with exaggerated amygdala activity that may be reflected in differential vagal outputs via the nucleus ambiguous or the dorsal nucleus of the vagus (see Figure 2).

\section{Treatment}

In terms of pharmacological interventions for treating PTSD, the traditional approach has been to broadly address the symptoms of the disorder with a combination of benzodiazepines or serotonin-selective reuptake inhibitors (SSRIs) and CBT. In fact, SSRIs (eg, sertraline, paroxetine) are widely recognized as the first-line treatment for PTSD. ${ }^{55,56}$ However, the need for enhanced development of pharmacotherapies for PTSD is evident in the consistently low response rates reported in addition to an observed lack of full remission in many patients. ${ }^{87,88}$ In addition, pharmacological treatment is indicated in situations in which (1) the patient is amenable to receiving drug treatment, (2) there is a high degree of comorbid symptomatology (eg, major depression, panic disorder), and (3) full-scale CBT treatment is currently unavailable. ${ }^{59}$

In many cases, a specific symptom cluster will dominate a patient's clinical presentation and cause the highest degree of distress and functional impairment, ${ }^{89}$ either in individuals with a full diagnosis of PTSD or in trauma-exposed individuals who only endorse a subset of PTSD symptom clusters (subsyndromal PTSD). The treatment of subsyndromal PTSD,

Table I Psychophysiological correlates of reexperiencing symptoms

\begin{tabular}{|c|c|c|c|c|}
\hline \multirow{3}{*}{$\begin{array}{l}\text { Reexperiencing symptoms } \\
\text { Intrusive/distressing thoughts }\end{array}$} & \multicolumn{4}{|c|}{ Response to danger cue } \\
\hline & \multicolumn{2}{|c|}{ Startle $(\mu \mathbf{V})$} & \multicolumn{2}{|c|}{ RSA (HF-HRV) } \\
\hline & $r=0.28$ & $P=0.001 * *$ & $r=0.14$ & $P=0.08$ \\
\hline Recurrent bad nightmares & $r=0.03$ & ns & $r=0.11$ & ns \\
\hline Experience flashbacks & $r=0.08$ & ns & $r=0.22$ & $P=0.005^{* *}$ \\
\hline Intense emotional upset at reminder & $r=0.17$ & $P=0.03^{*}$ & $r=0.13$ & $P=0.09$ \\
\hline Intense physical reactions at reminder & $r=0.16$ & $P=0.04^{*}$ & $r=0.15$ & $P=0.05^{*}$ \\
\hline
\end{tabular}

Note: Startle and RSA data were collected during a fear-conditioning session. The symptoms (as assessed with the PSS) are correlated with responses during presentation of the danger cue, ie, the reinforced conditioned stimulus (CS+).

Abbreviations: RSA, respiratory sinus arrhythmia; HF-HRV, high-frequency heart-rate variability. 
as discussed by Shea et $\mathrm{al}^{17}$ is an important concern for clinicians in that PTSD symptoms that are under the criteria for a full PTSD diagnosis should be the focus of interventions as well. In many cases, it is possible to target specific symptom clusters when considering psychopharmacotherapy. A small number of drugs representing multiple classes have proven effective in treating the reexperiencing symptoms associated with PTSD. For example, the SSRIs fluoxetine and sertraline were shown to be effective in reducing intrusive thoughts and reexperiencing. ${ }^{90-92}$ In addition, the antipsychotics risperidone and quetiapine (both as a primary treatment and as an adjunct $)^{93-95}$ significantly decreased intrusive symptoms such as flashbacks in several clinical trials. Further, the anticonvulsant, carbamazepine, ${ }^{96}$ and the opioid receptor antagonists, naltrexone ${ }^{97}$ and nalmefene, ${ }^{98}$ have reduced reexperiencing symptoms such as nightmares and flashbacks.

The recommendation for patients in whom reexperiencing symptoms are dominant in their psychiatric profile, evidence suggests the use of an SSRI as a first-line pharmacotherapy with the clinician having the option of altering the course of treatment to a different drug class if the patient proves to be a refractory PTSD case. A small number of studies have examined neuroanatomical changes in response to treatment. Two studies examined effects of SSRIs on hippocampal volume, a structure that is part of the limbic circuitry and closely connected to the amygdala. Both studies found that PTSD patients showed increased volume posttreatment, thereby eliminating pretreatment group differences in hippocampal size. ${ }^{99,100}$ On the other hand, psychotherapy does not appear to affect the volume of the hippocampus. ${ }^{101}$ Inasmuch as the limbic system is related to reexperiencing symptoms, these data suggest that SSRIs may be more effective in treating the underlying neurobiology of these symptoms.

\section{Avoidance symptoms Clinical snapshots}

A 30-year-old male OIF/OEF combat veteran avoids thoughts or discussion about combat-related experiences, avoids reminders of combat, including military friends who remind him of combat and who may want to talk about combat experiences. The patient avoids activities that remind him of combat, even going so far as to quit a job in which the workplace smelled similar to the combat zone. The patient has difficulty connecting emotionally with others, although he reports previously being very social. Prior to combat exposure, he enjoyed exploring new places and things, but now he isolates and is fearful of new situations.
A 28-year-old female combat veteran does not have intrusive thoughts of her childhood sexual abuse or exposure to mortar blasts in Iraq and denies flashbacks or nightmares with traumatic content. She reports worsening of chronic social avoidance/isolation, avoidance of crowds, emotional numbing, and emotional detachment since returning from Iraq.

\section{Neurobiological underpinnings}

Although avoidance symptoms may not be as easily apparent as reexperiencing or hyperarousal symptoms, they frequently contribute to long-term maintenance of PTSD. Avoidance of trauma reminders often includes avoidance of PTSD therapy, which may be especially pronounced with exposure-based psychotherapy. Furthermore, emotional numbing and detachment can reduce the number of patient opportunities to benefit from social support, a significant aid to recovery. ${ }^{102}$ Dissociation is frequently related to avoidance and detachment symptoms; this symptom profile differs to such an extent compared with other PTSD symptom profiles that these patients are sometimes classified as a "dissociative subtype". ${ }^{103}$

Studies exploring the neurobiology of PTSD avoidance symptoms and related dissociation have yielded contradictory results. Avoidance symptoms appear to be associated with PNS activity. For example, PTSD patients who show a more dissociative response have decreased heart-rate changes during script-driven imagery ${ }^{104}$ in addition to different neurobiological activation in limbic and PFC areas. ${ }^{103}$ Furthermore, a study of sexual assault survivors with PTSD found that increased dissociation was related to reduced skin conductance responses. ${ }^{47} \mathrm{~A}$ large study of Vietnam veterans with dissociative symptoms, however, did not replicate physiological suppression. ${ }^{105}$ It appears as though the degree of traumatization contributes to the heterogeneity of psychophysiological responses. A recent study by McTeague and colleagues found that PTSD patients who had experienced multiple traumas had lower skin conductance and startle responses to threat stimuli than PTSD patients who had a single traumatic event; multiple trauma PTSD patients also exhibited higher levels of avoidance and emotional numbing than single trauma victims. ${ }^{106}$

Preliminary data from a traumatized civilian population observed at Grady Hospital in urban Atlanta, which includes a significant number of patients with a history of polytrauma, support a negative relationship between avoidance symptom severity and skin conductance responses, indicating a significant role of the PNS in this symptom domain. The notion of the PNS as a neurobiological substrate for PTSD avoidance 
Table 2 Psychophysiological correlates of avoidance symptoms

\begin{tabular}{|c|c|c|c|c|}
\hline \multirow[t]{2}{*}{ Avoidance symptoms } & \multicolumn{4}{|c|}{ Response to danger cue } \\
\hline & $\operatorname{SCR}(\mu s)$ & & RSA (HF-HRV) & \\
\hline Avoid thoughts/feelings & $r=-0.36$ & $P=0.000 I^{* * *}$ & $r=0.13$ & ns \\
\hline Avoid activities/situations/places & $r=-0.25$ & $P=0.009 * *$ & $r=-0.16$ & ns \\
\hline Can't recall important aspects & $r=-0.09$ & ns & $r=0.08$ & ns \\
\hline Loss of interest in activities & $r=-0.30$ & $P=0.002 * *$ & $r=0.52$ & $P=0.0 I^{*}$ \\
\hline Detached/cut-off from others & $r=-0.25$ & $P=0.0 I^{*}$ & $r=0.48$ & $P=0.02 *$ \\
\hline Impaired range of emotions & $r=-0.14$ & ns & $r=0.21$ & ns \\
\hline Changed future plans/hopes & $r=-0.23$ & $P=0.02 *$ & $r=0.09$ & ns \\
\hline
\end{tabular}

Note: SCR and RSA were collected during a fear-conditioning session. The symptoms (as assessed with the PSS) are correlated with responses during presentation of the danger cue, ie, the reinforced conditioned stimulus (CS+).

Abbreviations: SCR, skin conductance response; RSA, respiratory sinus arrhythmia; HF-HRV, high-frequency heart-rate variability.

symptoms is supported by a positive correlation between avoidance symptoms and RSA, an index of PNS activity (see Table 2). ${ }^{107}$ Although avoidance and detachment were associated with physiological markers of fear, restricted range of emotion and memory impairment were not. The proposed revisions for the 5th edition of the DSM separate avoidance and emotional numbing into different clusters and will also expand the emotional numbing to include persistent negative emotions. Although it is possible that these two categories of symptoms have different neurobiological underpinnings, our data suggest that avoidance and detachment may be related. However, more data on the neurobiology of individual symptoms is needed before such conclusions can be made.

\section{Treatment}

The treatment recommendation for individuals who are predominantly avoidant is one of several CBT techniques including PE and CPT with the added caveat that individuals who continue to be avoidant in response to traditional CBT methods be given the opportunity to experience VR or other alternative measures. Emotional activation, which is one of the necessary components of effective exposure therapy, ${ }^{65}$ may be hindered by numbing symptoms. As mentioned above, the next edition of the DSM may differentiate avoidance and emotional numbing; future clinical studies of treatment efficacy may selectively target these symptoms.

As described earlier, a number of drug classes have been used to treat PTSD symptoms pharmacologically. The most effective pharmacotherapies to date have been antidepressant SSRIs ${ }^{89}$ It has been widely demonstrated that SSRIs are effective in reducing a number of PTSD symptoms across clusters; ${ }^{55}$ this includes several groups reporting a decrease in avoidant symptoms with the administration of the SSRIs fluoxetine, ${ }^{90}$ escitalopram, ${ }^{108}$ and sertraline. ${ }^{109}$ The antipsychotic quetiapine $e^{94,110,111}$ and the mood stabilizer lamotrigine ${ }^{12}$ have shown some efficacy in ameliorating avoidant PTSD symptoms, but a preponderance of the empirical evidence supports the use of an SSRI coupled with a form of CBT and/or PE.

\section{Hyperarousal symptoms Clinical snapshots}

A 31-year-old male combat veteran reports angry mood, exaggerated startle, daily intrusive memories, irritability, constant visual scanning of his environment, and worries about people "challenging" him when he goes out in public. This patient sometimes sleeps in his car because he feels more comfortable there and is better able to be alert. Patient states, "If I can control my anger I can go back to work."

A 26-year-old male combat veteran reports anger, irritability, and extreme emotional reactivity to triggers such as "people in his space."

\section{Neurobiological underpinnings}

The hyperarousal symptoms of PTSD can often lead to more generalized impairments in function due to either sleep disturbance or, more frequently, anger issues and subsequent occupational problems. As seen in the clinical snapshots above, anger is frequently reported as part of this symptom cluster. It is often a spouse or family members who encourages a patient to seek treatment for these issues.

Despite the observations that exaggerated startle is a cardinal symptom of PTSD and sympathetic nervous system arousal can be easily measured with skin conductance, empirical findings have not yielded consistent results. Most previous studies investigating PTSD-related exaggerated startle have found that baseline startle is only heightened within a relatively short time after a traumatic experience. ${ }^{113}$ On the other hand, elevated basal heart-rate has been observed in a number of studies with PTSD patients. ${ }^{114-116}$ This elevation appears to be related to the chronicity of the disorder, indicating greater cardiovascular risk for PTSD patients. ${ }^{114}$ 
In our study of Croatian veterans, we found that those with PTSD had higher heart-rates of 10 beats per minute (bpm) on average than controls, even 10 years after their trauma. ${ }^{117}$ These data suggest alterations in parasympathetic activity in addition to sympathetic system overactivation, which is likely to contribute to cardiovascular risk. ${ }^{115}$

Some hyperarousal symptoms, such as exaggerated vigilance, may be associated with a poor ability to discriminate between danger and safety cues. As discussed previously, impaired inhibition of fear-potentiated startle to safety cues is associated with PTSD symptom severity in combat veterans. ${ }^{28}$ In a recent study of a highly traumatized civilian population, we found that impaired fear inhibition was specific to PTSD rather than depression; moreover, PTSD subjects with the highest hyperarousal symptoms had the greatest impairment in fear inhibition ${ }^{29}$ (Table 3). Although other studies have not specifically focused on hyperarousal symptoms, heightened fear responses to safety cues (or overgeneralization of fear responses) have been frequently observed in PTSD subjects. ${ }^{118}$ A recent fMRI study found that fear conditioning in PTSD subjects was associated with amygdala hyperactivity in response to the dangerous context and vmPFC hypoactivity to the safety context. ${ }^{49}$ Taken together, these data suggest that the reciprocal connections between the amygdala and PFC may underlie some hyperarousal symptoms. However, some neurobiological evidence points to broader brain structures associated with hyperarousal symptoms. One imaging study looked at regional cerebral blood flow in PTSD patients who presented with high levels of hyperarousal symptoms, including severe aggression and irritability, and found greater activation in the nucleus accumbens. ${ }^{119} \mathrm{~A}$ case study of a Croatian combat veteran with PTSD predominantly manifesting hyperarousal symptoms found that pretreatment hyperactivation of the amygdala and nucleus accumbens was normalized after a year of psychotherapy. ${ }^{120}$

Table 3 Psychophysiological correlates of hyperarousal symptoms

\begin{tabular}{llllll}
\hline $\begin{array}{l}\text { Hyperarousal } \\
\text { symptoms }\end{array}$ & \multicolumn{4}{l}{ Response to safety cue } \\
\cline { 2 - 6 } & \multicolumn{2}{l}{ Startle $(\mu \mathbf{V})$} & RSA (HF-HRV) \\
\hline Difficulty sleeping & $r=0.06$ & $\mathrm{~ns}$ & $r=0.08$ & $\mathrm{~ns}$ \\
Irritable/anger outbursts & $r=0.04$ & $\mathrm{~ns}$ & $r=0.47$ & $P=0.03^{*}$ \\
Difficulty concentrating & $r=0.23$ & $P=0.03^{*}$ & $r=0.47$ & $P=0.03^{*}$ \\
Overly alert & $r=0.18$ & $\mathrm{~ns}$ & $r=0.37$ & $\mathrm{~ns}$ \\
Jumpier/easily startled & $r=0.22$ & $P=0.04 *$ & $r=0.38$ & $\mathrm{~ns}$ \\
\hline
\end{tabular}

Note: Startle and RSA data were collected during a fear conditioning session. The symptoms (as assessed with the PSS) are correlated with responses during presentation of the safety cue, ie, the nonreinforced conditioned stimulus (CS-). Abbreviations: RSA, respiratory sinus arrhythmia; HF-HRV, high frequency heartrate variability.
Another line of evidence that relates to chronic hyperarousal is diminished habituation in PTSD that may be a marker for hypervigilance. Habituation, like extinction, results in decreased responding to repeated stimulation. ${ }^{121}$ Unlike extinction, however, habituation does not involve associative learning and is therefore not predicated on fear-conditioning phenomena. Habituation is an evolutionarily older mechanism and may not involve higher brain areas, such as the PFC or even the limbic system; ${ }^{121}$ deficits in habituation may be mediated by the autonomic system. Startle habituation deficits have been reported in Israeli patients who developed PTSD after trauma - the startle deficit was seen at an assessment of 4 months after trauma, indicating that it developed as part of the other PTSD symptoms. ${ }^{122}$ Our recent study of Croatian veterans with PTSD found that a higher proportion of PTSD subjects did not show linear habituation curves compared with controls. ${ }^{117}$

\section{Treatment}

As illustrated in Figure 1, hyperarousal symptoms of PTSD include sleep disturbances, anger and irritability, and explosive behaviors. From a psychopharmacological perspective, a number of drug treatments have been explored as a means of reducing hyperarousal. Similar to the previously discussed symptom clusters, SSRIs such as fluoxetine, ${ }^{91}$ escitalopram, ${ }^{108}$ and sertraline ${ }^{109}$ have shown significant efficacy in reducing hyperarousal symptoms. The mood stabilizers lithium ${ }^{123}$ and valproic acid, ${ }^{124}$ as well as the antipsychotic olanzapine ${ }^{125}$ have also been reported to decrease hyperarousal with the latter having a profound effect on sleep disturbances. Furthermore, $\alpha-1$ adrenergic receptors have been implicated in PTSD-related sleep disturbances and hypervigilance. ${ }^{126}$ Based on the findings of randomized clinical trials, ${ }^{126-128}$ open label studies, ${ }^{129-131}$ and case reports, ${ }^{132,133}$ prazosin appears to be a reliable adjunct treatment for PTSD with specific benefits for ameliorating nightmares. Thus, the recommendation for patients presenting with these symptoms is to prescribe hypnotics or atypical antipsychotics for insomnia or prazosin for nightmares.

\section{Tailoring individual treatment plans for PTSD: future directions}

Future treatment strategies for combat-related PTSD may be governed by a shift toward personalized medicine. The identification of particular environmental risk factors, genotypes, or gene expression patterns specific to trauma exposure and PTSD may dictate which treatment regimens will be most effective for a particular patient. An area of increasing interest to mental health clinicians is pharmacogenetics in which 
the goal is to genotype patients before starting a particular psychiatric pharmacological therapy as a means of determining a patient's likelihood of a therapeutic response, ${ }^{134}$ Further, the identification of potential genetic variants that increase susceptibility for developing psychiatric illness would be a particularly important tool for advancing treatment options for PTSD and related anxiety disorders.

An example of such a variant may exist in the gene that codes for the serotonin transporter (5-HTT); a transmembrane, presynaptic protein that mediates the reuptake of serotonin from the synaptic cleft following transmitter release. A genetic polymorphism has been identified in humans containing a 44-bp deletion in the promoter region (frequently termed the short or $S$ allele) that reduces transcription of the gene, translation of the messenger RNA, and 5-HTT expression on the presynaptic membrane. ${ }^{135-138}$ The 5-HTT " $S$ " allele was recently linked to a predisposition for the development of PTSD following a traumatic event. For example, in a gene-environment study of Hurricane Katrina victims, those individuals who possessed the " $S$ " allele and had low levels of social support were more likely to develop PTSD and major depression. ${ }^{139}$ A review of the genetics of PTSD is beyond the scope of this review, and there are several reviews currently available in the literature. ${ }^{140-142}$

There are a small number of genetic variants and environmental interactions with strong empirical evidence for influencing the development of PTSD and with the greatest potential for impacting future therapeutic approaches to combat-related PTSD. Environmental factors that appear to have a strong influence on the development of PTSD after a traumatic event include one's experiences during childhood, as well as one's social support network after a traumatic event. Genetic variants that appear to influence an individual's risk for PTSD after trauma include genes related to the hypothalamic-pituitary-adrenal axis, the ascending brainstem locus coeruleus-noradrenergic system, and the limbic amygdalar frontal pathway that mediates fear processing. ${ }^{141,143-145}$ Within the latter neural systems, the serotonin, dopamine, glucocorticoid receptor, $\gamma$-aminobutyric acid, apolipoprotein, brainderived neurotrophic factor, and neuropeptide $Y$ systems have all been implicated in the genetic contribution to PTSD onset following a traumatic event.

An accumulating body of evidence suggests that PTSD is the result of complex gene-environment interactions. For example, as part of the largest genetic study of PTSD to date, Binder and colleagues ${ }^{146}$ studied the relationship between FKBP5 polymorphisms and past child abuse on one's susceptibility to developing PTSD. FKBP5 is a cochaperone protein that interacts with heat shock protein 90, a molecular chaper- one itself, that maintains neuronal viability and binds to the glucocorticoid receptor. ${ }^{147}$ Four single nucleotide polymorphisms (SNPs) of the FKBP5 gene (rs9296158, rs3800373, rs1360780, and rs9470080) significantly interacted with child abuse severity (as measured by the traumatic events inventory) to predict adult PTSD symptoms (as measured by the PTSD Symptom Scale).

It is important to note that the extant gene-environment investigations of PTSD have examined the relationship between environmental factors (eg, social support) and either a DSM-IV diagnosis of PTSD or the overall clinical presentation of PTSD (eg, total PSS or Clinician Administered PTSD Scale score). There have been no studies, to our knowledge, that have investigated gene-environment relationships to specific symptom clusters. This is an intriguing area for future research efforts.

Novel pharmacological approaches that enhance fear extinction are currently being tested. The use of D-cycloserine, a partial NMDA receptor agonist, as a treatment for PTSD arose as a result of numerous preclinical studies implicating NMDA glutamate receptor activity in learning and memory processes. ${ }^{148-151}$ Researchers administered DCS to rats immediately before extinction training and then subsequently found greater extinction retention 24 hours later. ${ }^{152}$ As mentioned earlier, an important aspect of fear learning of concern to clinicians is the return of fear following exposure therapy (extinction training). DCS, in addition to its enhancement of extinction retention, has also been shown to reduce reinstatement of fear in rats. ${ }^{153}$ Barbara Rothbaum and her collaborators at Emory University recently investigated the use of DCS in combination with VR exposure (VRE) therapy for the fear of heights. ${ }^{154}$ After treatment, those patients who received DCS in combination with VRE showed significantly greater improvement compared with those who received placebo and VRE. Importantly, patients experienced a generalization of reduced fear of heights that extended beyond the virtual elevator context into "real world" contexts. DCS is currently being investigated as adjunct to exposure therapy in PTSD.

Recent studies have identified CB1 cannabinoid receptors as a potential therapeutic target for drug treatment in humans based on the finding that CB1 agonist administration has been shown to facilitate extinction in rats and mice. ${ }^{155}$ As putative drugs acting on the $\mathrm{CB} 1$ receptor and cannabinoid reuptake processes are developed, this potential avenue of pharmacotherapy will be further explored. As seen from the above studies, these exploratory new drugs have the potential to enhance extinction learning during exposure sessions and to prevent relapse of 
symptoms following the cessation of exposure therapy. Given that these drugs enhance fear inhibition, they may reduce both reexperiencing and hyperarousal symptoms.

It seems likely that the future treatment of PTSD will encompass highly individualized treatment in which an individual's risk for developing PTSD prior to trauma exposure (eg, during predeployment training), as well as his or her likelihood of responding well to pharmacological and behavioral therapies, is assessed across multiple dimensions including environmental, genetic, and psychophysiological. Consideration of genetic risk factors, as well as individual variability in clinical presentation across the different PTSD symptom clusters, will allow for treatment strategies tailored to each individual patient, resulting in greater treatment efficacy and improved quality of life for PTSD patients.

\section{Acknowledgment}

This work was supported by grants awarded to SDN from the Emory University Research Committee (Atlanta Clinical and Translational Science Institute), NARSAD, and the Department of Defense/Congressionally Directed Medical Research Program (CDMRP). We thank Ilana Olin for her assistance in the preparation of this manuscript.

\section{Disclosure}

The authors report no conflicts of interest in this work.

\section{References}

1. Breslau N, Kessler RC, Chilcoat HD, Schultz LR, Davis GC, Andreski P. Trauma and posttraumatic stress disorder in the community: the 1996 Detroit Area Survey of Trauma. Arch Gen Psychiatry. 1998;55: 626-632.

2. Galea S, Resnick H, Ahern J, et al. Posttraumatic stress disorder in Manhattan, New York City, after the September 11th terrorist attacks. $J$ Urban Health. 2002;79:340-353.

3. Schuster MA, Stein BD, Jaycox LH, et al. A National Survey of Stress Reactions after the 2001 Sep 11, Terrorist Attacks. $N$ Engl J Med. 2001;345:1507-1512.

4. Kulka RA, Schlenger WE, Fairbank JA, et al. Trauma and the Vietnam War Generation: Report of Findings from the National Vietnam Veterans Readjustment Study. New York, NY: Brunner/Mazel; 1990.

5. Hoge CW, Castro CA, Messer SC, McGurk D, Cotting DI, Koffman RL. Combat duty in Iraq and Afghanistan, mental health problems, and barriers to care. $N$ Engl J Med. 2004;351:13-22.

6. Breslau N, Wilcox HC, Storr CL, Lucia VC, Anthony JC. Trauma exposure and posttraumatic stress disorder: a study of youths in urban America. J Urban Health. 2004;81:530-544.

7. Schwartz AC, Bradley RL, Sexton M, Sherry A, Ressler KJ. Posttraumatic stress Ddisorder among African Americans in an inner city mental health clinic. Psychiatr Serv. 2005;56:212-215.

8. Switzer GE, Dew MA, Thompson K, Goycoolea JM, Derricott T, Mullins SD. Posttraumatic stress disorder and service utilization among urban mental health center clients. J Trauma Stress. 1999;12: 25-39.

9. Alim TN, Graves E, Mellman TA, et al. Trauma exposure, posttraumatic stress disorder and depression in an African-American primary care population. $J$ Natl Med Assoc. 2006;98:1630-1636.
10. Schilling EA, Aseltine RHJ, Gore S. Adverse childhood experiences and mental health in young adults: a longitudinal survey. BMC Public Health. 2007;7:1-10.

11. Jones $\mathrm{C}$, Harvey AG, Brewin CR. Traumatic brain injury, dissociation, and posttraumatic stress disorder in road traffic accident survivors. J Trauma Stress. 2005;18:181-191.

12. Rothbaum BO, Kozak MJ, Foa EB, Whitaker DJ. Posttraumatic stress disorder in rape victims: autonomic habituation to auditory stimuli. J Trauma Stress. 2001;14:283-293.

13. Krause ED, Kaltman S, Goodman L, Dutton MA. Role of distinct PTSD symptoms in intimate partner reabuse: a prospective study. J Trauma Stress. 2006;19:507-516.

14. Galea S, Brewin CR, Gruber M, et al. Exposure to hurricane-related stressors and mental illness after Hurricane Katrina. Arch Gen Psychiatry. 2007;64:1427-1434.

15. Ben-Ezra M, Shrira A, Palgi Y. The hidden face of Haiti's tragedy. Science. 2010;327:1325.

16. APA. Diagnostic and Statistical Manual of Mental Disorders $(D S M-I V)$. 4th ed. Washington, D.C.: American Psychiatric Association; 1994.

17. Shea MT, Vujanovic AA, Mansfield AK, Sevin E, Liu F. Posttraumatic stress disorder symptoms and functional impairment among OEF and OIF National Guard and Reserve veterans. Journal of traumatic stress. 2010;23:100-107.

18. Frewen PA, Lanius RA. Toward a psychobiology of posttraumatic self-dysregulation: reexperiencing, hyperarousal, dissociation, and emotional numbing. Ann NY Acad Sci. 2006;1071:110-124.

19. Yehuda R, Schmeidler J, Siever LJ, Binder-Brynes K, Elkin A. Individual differences in posttraumatic stress disorder symptom profiles in Holocaust survivors in concentration camps or in hiding. J Trauma Stress. 1997;10:453-463.

20. Keane TM, Zimering RT, Caddell JM. A behavioral formulation of posttraumatic stress disorder in Vietnam veterans. Behavior Therapist. 1985;8:9-12.

21. Friedman MJ. Prevention of psychiatric problems among military personnel and their spouses. $N$ Engl J Med. 2010;362:168-170.

22. Amstedter AB, Nugent NR, Koenen KC. Genetics of PTSD: fear conditioning as a model for future research. Psychiatr Ann. 2009;39: 338-369.

23. Blanchard EB, Kolb LC, Gerardi RJ, Ryan DH, Pallmeyer TP. Cardiac response to relevant stimuli as an adjunctive tool for diagnosing post-traumatic stress disorder in Vietnam veterans. Behav Ther. 1986; 17:592-606.

24. Pitman RK, Orr SP, Forgue DF, de Jong JB, Claiborn JM. Psychophysiologic assessment of posttraumatic stress disorder imagery in Vietnam combat veterans. Arch Gen Psychiatry. 1987;44:970-975.

25. Mowrer OH. Learning Theory and Behavior. New York, NY: Wiley; 1960.

26. Levis DJ. Extrapolation of two-factor learning theory of infrahuman avoidance behavior to psychopathology. Neurosci Biobehav Rev. 1981; 5:355-370.

27. Rothbaum BO, Schwartz AC. Exposure therapy for posttraumatic stress disorder. Am J Psychother. 2002;56:59.

28. Jovanovic T, Norrholm SD, Fennell JE, et al. Posttraumatic stress disorder may be associated with impaired fear inhibition: relation to symptom severity. Psychiatry Res. 2009;176(1-2);151-160.

29. Jovanovic T, Norrholm SD, Blanding NQ, et al. Impaired fear inhibition is a biomarker of PTSD but not depression. Depress Anxiety. 2010;27:244-51.

30. Brewin CR, Holmes EA. Psychological theories of posttraumatic stress disorder. Clin Psychol Rev. 2003;23:339-376.

31. Foa EB, Steketee G, Rothbaum BO. Behavioral/cognitive conceptualizations of post-traumatic stress disorder. Behav Ther. 1989; 20:155-176.

32. Jovanovic T, Ressler KJ. How the neurocircuitry and genetics of fear inhibition may inform our understanding of PTSD. Am J Psychiatry. 2010;167:648-662. 
33. Bremner J, Staib L, Kaloupek DD, Southwick S, Soufer RR, Charney D. Neural correlates of exposure to traumatic pictures and sound in Vietnam combat veterans with and without posttraumatic stress disorder: a positron emission tomography study. Biol Psychiatry. 1999;45:806-816.

34. Liberzon I, Taylor SF, Amdur R, et al. Brain activation in PTSD in response to trauma-related stimuli. Biol Psychiatry. 1999;45: 817-826.

35. Liberzon I, Sripada CS. The functional neuroanatomy of PTSD: a critical review. Prog Brain Res. 2007;167:-151-69.

36. Rauch SL, van der Kolk BA, Fisler RE, et al. A symptom provocation study of posttraumatic stress disorder using positron emission tomography and script-driven imagery. Arch Gen Psychiatry. 1996;53:380-387.

37. Shin LM, McNally RJ, Kosslyn SM, et al. Regional cerebral blood flow during script-driven imagery in childhood sexual abuserelated PTSD: A PET investigation. Am J Psychiatry. 1999;156: 575-584.

38. Protopopescu X, Pan H, Tuescher O, et al. Differential time courses and specificity of amygdala activity in posttraumatic stress disorder subjects and normal control subjects. Biol Psychiatry. 2005;57:464-473.

39. Rauch SL, Whalen PJ, Shin LM, et al. Exaggerated amygdala response to masked facial stimuli in posttraumatic stress disorder: a functional MRI study. Biol Psychiatry. 2000;47:769-776.

40. Shin LM, Wright CI, Cannistraro PA, et al. A functional magnetic resonance imaging study of amygdala and medial prefrontal cortex responses to overtly presented fearful faces in posttraumatic stress disorder. Arch Gen Psychiatry. 2005;62:273-281.

41. Bremner JD, Vermetten E, Vythilingam M, et al. Neural correlates of the classic color and emotional stroop in women with abuse-related posttraumatic stress disorder. Biol Psychiatry. 2004;55:612-620.

42. Shin LM, Bush G, Whalen PJ, et al. Dorsal anterior cingulate function in posttraumatic stress disorder. J Trauma Stress. 2007;20:701-712.

43. Mannie ZN, Norbury R, Murphy SE, Inkster B, Harmer CJ, Cowen PJ.Affective modulation of anterior cingulate cortex in young people at increased familial risk of depression. Br J Psychiatry. 2008; 192:356-361.

44. Davis M, Falls WA, Campeau S, Kim M. Fear-potentiated startle: a neural and pharmacological analysis. Behav Brain Res. 1993; 58:175-198.

45. Porges SW. The polyvagal theory: phylogenetic substrates of a social nervous system. Int J Psychophysiol. 2001;42:123-146.

46. Leite-Panissi CRA, Coimbra NC, Menescal-de-Oliveira L. The cholinergic stimulation of the central amygdala modifying the tonic immobility response and antinociception in guinea pigs depends on the ventrolateral periaqueductal gray. Brain Res Bull. 2003; 60:167-178.

47. Griffin MG, Resick PA, Mechanic MB. Objective assessment of peritraumatic dissociation: psychophysiological indicators. Am J Psychiatry. 1997;154:1081-1088.

48. Phelps EA, Delgado MR, Nearing KI, LeDoux JE. Extinction learning in humans: role of the amygdala and vmPFC. Neuron. 2004;43:897-905.

49. Milad MR, Pitman RK, Ellis CB, et al. Neurobiological basis of failure to recall extinction memory in posttraumatic stress disorder. Biol Psychiatry. 2009;66:1075-1082.

50. Davis M. Role of NMDA receptors and MAP kinase in the amygdala in extinction of fear: clinical implications for exposure therapy. Eur J Neurosci. 2002;16:395-398.

51. Falls WA, Miserendino MJ, Davis M. Extinction of fear-potentiated startle: blockade by infusion of an NMDA antagonist into the amygdala. J Neurosci. 1992;12:854-863.

52. Lu KT, Walker DL, Davis M. Mitogen-activated protein kinase cascade in the basolateral nucleus of amygdala is involved in extinction of fear-potentiated startle. J Neurosci. 2001;21:RC162-RC166.

53. Lee H, Kim J. Amygdalar NMDA receptors are critical for new fear learning in previously fear-conditioned rats. J Neurosci. 1998; 18:8444-8454.
54. Walker DL, Davis M. The role of amygdala glutamate receptors in fear learning, fear-potentiated startle, and extinction. Pharmacol Biochem Behav. 2002;71:379-392.

55. Stein DJ, Ipser J, McAnda N. Pharmacotherapy of posttraumatic stress disorder: a review of meta-analyses and treatment guidelines. CNS Spectr. 2009;14:25-31.

56. Berger W, Mendlowicz MV, Marques-Portella C, et al. Pharmacologic alternatives to antidepressants in posttraumatic stress disorder: a systematic review. Prog Neuropsychopharmacol Biol Psychiatry. 2009;33:169-180.

57. Hageman I, Andersen HS, Jorgensen MB. Post-traumatic stress disorder: a review of psychobiology and pharmacotherapy. Acta Psychiatrica Scandinavica. 2001;104:411-422.

58. Davis LL, English BA, Ambrose SM, Petty F. Pharmacotherapy for post-traumatic stress disorder: a comprehensive review. Expert Opin Pharmacother. 2001;2:1583-1595.

59. Friedman M. Post Traumatic and Acute Stress Disorders: The Latest Assessment and Treatment Strategies. 4th ed. Kansas City, MO: Dean Psych Press Corporation; 2006.

60. Follette VM, Ruzek JL, Abueg FR. Cognitive Behavioral Therapies for Trauma. New York, NY: Guilford; 1998.

61. Tarrier N, Sommerfield C, Pilgrim H. Relatives' expressed emotion(EE) and PTSD treatment outcome. Psychol Med. 1999;29:801-811.

62. Rothbaum BO, Hodges LF, Ready D, Graap K, Alarcon RD. Virtual reality exposure therapy for Vietnam veterans with posttraumatic stress disorder. J Clin Psychiatry. 2001;62:617-622.

63. Medicine Io. Treatment of Posttraumatic Stress Disorder: An Assessment of the Evidence. Washington D.C.: National Academy of Science; 2008

64. Van Etten ML, Taylor S. Comparative efficacy of treatments for post-traumatic stress disorder: A meta-analysis. Clin Psychol Psychother. 1998;5:126-144.

65. Rothbaum BO, Meadows EA, Resick P, Foy DW. CognitiveBehavioral Therapy. In: Foa EB, Friedman MI, Keane T, eds. Effective Treatments for Posttraumatic Stress Disorder: Practice Guidelines from the International Society for Traumatic Stress Studies. New York, NY: Guilford Press; 2000:60-83.

66. Foa EB. Psychosocial treatment of posttraumatic stress disorder. J Clin Psychiatry. 2000;61:43-48.

67. Rothbaum BO, Hodges L, Smith S, Lee JH, Price L. A controlled study of virtual reality exposure therapy for the fear of flying. J Consult Clin Psychol. 2000;68:1020-1026.

68. Foa EB, Huppert JD, Cahill SP. Emotional processing theory: an update. In: Rothbaum BO, editor. Pathological Anxiety. New York, NY: Guilford Press; 2006:3-24.

69. Difede J, Cukor J, Jayasinghe N, et al. Virtual reality exposure therapy for the treatment of posttraumatic stress disorder following 2001 Sep 11. J Clinical Psychiatry. 2007;68:1639-1647.

70. Reger GM, Gahm GA, Rizzo AA, Swanson R, Duma S. Soldier evaluation of the virtual reality Iraq. Telemed J E Health. 2009;15: 101-104

71. Gerardi M, Rothbaum BO, Ressler K, Heekin M, Rizzo A. Virtual reality exposure therapy using a virtual Iraq: case report. J Trauma Stress. 2008;21:209-213.

72. Resick PA, Nishicki MK. Cognitive-processing therapy for sexual assault victims. J Consult Clin Psychol. 1992;60:748-756.

73. Resick PA, Nishith P, Weaver TL, Astin MC, Feuer CA. A comparison of cognitive-processing therapy with prolonged exposure and a waiting condition for the treatment of chronic posttraumatic stress disorder in female rape victims. J Consult Clin Psychol. 2002;70:867-879.

74. Norrholm SD, Jovanovic T, Rothbaum BO, et al. The Opitimization of Research and Clinical Applications for Combat-related Posttraumatic Stress Disorder (PTSD): Progress Through Modern Translational Methodologies. Hauppage, NY: Nova Science; 2010.

75. US Department of Health and Human Services Dgp. Clinical Practice Guideline No.5: Depression in Primary Care. Rockville, MD: AHCPR Publications; 1993. 
76. Lunney CA, Schnurr PP. Domains of quality of life and symptoms in male veterans treated for posttraumatic stress disorder. J Trauma Stress. 2007;20:955-964.

77. Schnurr PP, Lunney CA. Exploration of gender differences in how quality of life relates to posttraumatic stress disorder in male and female veterans. J Rehabil Res Dev. 2008;45:383-394.

78. Orr SP, Pitman RK, Lasko NB, Herz LR. Psychophysiological assessment of posttraumatic stress disorder imagery in World War II and Korean combat veterans. J Abnorm Psychol. 1993;102:152-159.

79. Pitman RK, Orr SP, Forgus DF, Altman B, de Jong JB, Herz LR. Psychophysiologic responses to combat imagery of Vietnam veterans with posttraumatic stress disorder versus other anxiety disorders. J Abnorm Psychol. 1990;99:49-54.

80. Shalev AY, Orr SP, Pitman RK. Psychophysiologic assessment of traumatic imagery in Israeli civilian patients with posttraumatic stress disorder. Am J Psychiatry. 1993;150:620-624.

81. Carson MA, Metzger LJ, Lasko NB, et al. Physiologic reactivity to startling tones in female vietnam nurse veterans with PTSD. J Traum Stress. 2007;20:657-666

82. Orr SP, Lasko NB, Metzger LJ, Berry NJ, Ahern CE, Pitman RK. Psychophysiologic assessment of women with posttraumatic stress disorder resulting from childhood sexual abuse. J Consult Clin Psychol. 1998;66:906-913.

83. Keane TM, Kolb LC, Kaloupek D, et al. Utility of psychophysiological measurement in the diagnosis of posttraumatic stress disorder: results from a Department of Veterans Affairs Cooperative Study. J Consult Clin Psychol. 1998;66:914-923.

84. Davis M. The role of the amygdala in fear-potentiated startle: implications for animal models of anxiety. Trends Pharmacol Sci 1992;13:35-41.

85. Pole N, Neylan TC, Otte C, Henn-Hasse C, Metzler TJ, Marmar CR. Prospective prediction of posttraumatic stress disorder symptoms using fear potentiated auditory startle responses. Biol Psychiatry. 2009;65:235-240.

86. Guthrie RM, Bryant RA. Extinction learning before trauma and subsequent posttraumatic stress. Psychosom Med. 2006;68: 307-811.

87. Zohar J, Amital D, Miodownik C, et al. Double-blind placebo-controlled pilot study of sertraline in military veterans with posttraumatic stress disorder. J Clin Psychopharmacol. 2002;22:190-195.

88. Stein MB, Kline NA, Matloff JL. Adjunctive olanzapine for SSRIresistant combat-related PTSD: a double-blind, placebo-controlled study. Am J Psychiatry. 2002;159:1777-1779.

89. Kozaric-Kovacic D. Psychopharmacotherapy of posttraumatic stress disorder. Croat Med J. 2008;49:459-475.

90. Connor KM, Sutherland SM, Tupler LA, Malik ML, Davidson JR. Fluoxetine in post-traumatic stress disorder. Randomised, double-blind study. Br J Psychiatry. 1999;175:17-22.

91. Nagy LM, Morgan CA, Southwick S, Charney D. Open prospective trial of fluoxetine for posttraumatic stress disorder. J Clin Psychopharmacol. 1993;13:107-113.

92. Kline NA, Dow BM, Brown SA, Matloff JL. Sertraline efficacy in depressed combat veterans with posttraumatic stress disorder. Am J Psychiatry. 1994;151(4):621.

93. Filteau MJ, Leblanc J, Bouchard RH. Quetiapine reduces flashbacks in chronic posttraumatic stress disorder. Can J Psychiatry. 2003; 48:282-283.

94. Hamner MB, Deitsch SE, Brodrick PS, Ulmer HG, Lorberbaum JP. Quetiapine treatment in patients with posttraumatic stress disorder: an open trial of adjunctive therapy. J Clin Psychopharmacol. 2003; 23:15-20.

95. Hamner MB, Faldowski RA, Ulmer HG, Frueh BC, Huber MG, Arana GW. Adjunctive risperidone treatment in post-traumatic stress disorder: a preliminary controlled trial of effects on comorbid psychotic symptoms. Int Clin Psychopharmacol. 2003;18:1-8.

96. Lipper S, Davidson JR, Grady TA, et al. Preliminary study of carbamazepine in the treatment of posttraumatic stress disorder. Psychosomatics. 1986;27:849-854.
97. Bills LJ, Kreisler K. Treatment of flashbacks with naltrexone. Am J Psychiatry. 1993;150:1430.

98. Glover H. A preliminary trial of nalmefene for the treatment of emotional numbing in combat veterans with post-traumatic stress disorder. Isr J Psychiatry Relat Sci. 1993;30:255-263.

99. Bremner JD, Vermetten E. Neuroanatomical changes associated with pharmacotherapy in posttraumatic stress disorder. Ann NY Acad Sci. 2004;1032:154-157.

100. Bossini L, Tavanti M, Lombardelli A, et al. Changes in hippocampal volume in patients with post-traumatic stress disorder after sertraline treatment. J Clinical Psychopharmacol. 2007;27:233-235.

101. Lindauer RAM, Oacute, N JL, et al. Effects of psychotherapy on hippocampal volume in out-patients with post-traumatic stress disorder: a MRI investigation. Psychol Med. 2005;35 1421-1431.

102. Andrews B, Brewin CR, Rose S. Gender, Social Support, and PTSD in Victims of Violent Crime. J Trauma Stress. 2003;16: 421-427.

103. Lanius RA, Williamson PC, Boksman K, et al. Brain activation during script-driven imagery induced dissociative responses in PTSD: a functional magnetic resonance imaging investigation. Biol Psychiatry. 2002;52:305-311.

104. Lanius RA, Williamson PC, Densmore M, et al. Neural correlates of traumatic memories in posttraumatic stress disorder: a functional MRI investigation. Am J Psychiatry. 2001;158:1920-1922.

105. Kaufman ML, Kimble MO, Kaloupek DG, et al. Peritraumatic dissociation and physiological response to trauma-relevant stimuli in Vietnam combat veterans with posttraumatic stress disorder. $J$ Nerv Ment Dis. 2002;190:167-174.

106. McTeague LM, Lang PJ, Laplante M-C, Cuthbert BN, Shumen JR, Bradley MM. Aversive imagery in posttraumatic stress disorder: trauma recurrence, comorbidity, and physiological reactivity. Biol Psychiatry. 2010;67:346-356.

107. Jovanovic T, Norrholm SD, Blanding NQ, et al. Physiological endophenotypes of postraumatic stress disorder symptoms. Am Coll Neuropsychopharmacol. 2008.

108. Robert S, Hamner MB, Ulmer HG, Lorberbaum JP, Durkalski VL. Open-label trial of escitalopram in the treatment of posttraumatic stress disorder. J Clin Psychiatry. 2006;67:1522-1526.

109. Brady KT, Pearlstein T, Asnis GM, et al. Efficacy and safety of sertraline treatment of posttraumatic stress disorder: a randomized controlled trial. JAMA. 2000;283:1837-1844.

110. Sokolski KN, Denson TF, Lee RT, Reist C. Quetiapine for treatment of refractory symptoms of combat-related post-traumatic stress disorder. Mil Med. 2003;168:486-489.

111. Kozaric-Kovacic D, Pivac N. Quetiapine treatment in an open trial in combat-related post-traumatic stress disorder with psychotic features. Int J Neuropsychopharmacol. 2007;10:253-261.

112. Hertzberg MA, Butterfield MI, Feldman ME, et al. A preliminary study of lamotrigine for the treatment of posttraumatic stress disorder. Biol Psychiatry. 1999;45:1226-1229.

113. Grillon C, Baas J. A review of the modulation of the startle reflex by affective states and its application in psychiatry. Clin Neurophysiol. 2003;114:1557-1579.

114. Buckley TC, Kaloupek DG. A meta-analytic examination of basal cardiovascular activity in posttraumatic stress disorder. Psychosom Med. 2001;63:585-594.

115. Hopper JW, Spinazzola J, Simpson WB, van der Kolk BA. Preliminary evidence of parasympathetic influence on basal heart rate in posttraumatic stress disorder. J Psychosom Res. 2006;60:83-90.

116. Cohen H, Benjamin J. Power spectrum analysis and cardiovascular morbidity in anxiety disorders. Auton Neurosci. 2006;128:1-8.

117. Jovanovic T, Norrholm SD, Sakoman AJ, Esterajher S, KozaricKovacic D. Altered resting psychophysiology and startle response in Croatian combat veterans with PTSD. Int J Psychophysiol. 2009;71:264-268. 
118. Lissek S, Powers AS, McClure EB, et al. Classical fear conditioning in the anxiety disorders: a meta-analysis. Behav Res Ther. 2005;43: 1391-1424.

119. Pavic L, Gregurek R, Petrović D, Varda R, Vukusić H, CrnkovićMarković S. Alterations in brain activation in posttraumatic stress disorder patients with severe hyperarousal symptoms and impulsive aggressiveness. Eur Arch Psychiatry Clin Neurosci. 2003;253:80-83.

120. Gregurek R, Petrović R. Psychotherapeutic effect on cerebral blood flow - case report. Lijec Vjesn. 2007;129:265-268.

121. Marks I, Tobena A. Learning and unlearning fear: a clinical and evolutionary perspective. Neurosci Biobehav Rev. 1990;14: 365-384.

122. Shalev AY, Peri T, Brandes D, Freedman S, Orr SP, Pitman RK. Auditory startle response in trauma survivors with posttraumatic stress disorder: a prospective study. Am J Psychiatry. 2000;157:255-261.

123. Kitchner I, Greenstein R. Low dose lithium carbonate in the treatment of post traumatic stress disorder: brief communication. Mil Med. 1985; 150:378-381.

124. Fesler FA. Valproate in combat-related posttraumatic stress disorder. J Clin Psychiatry. 1991;52:361-364.

125. Labbate LA, Douglas S. Olanzapine for nightmares and sleep disturbance in posttraumatic stress disorder (PTSD). Can J Psychiatry. 2000;45:667-668.

126. Raskind MA, Peskind ER, Hoff DJ, et al. A parallel group placebo controlled study of prazosin for trauma nightmares and sleep disturbance in combat veterans with post-traumatic stress disorder. Biol Psychiatry. 2007;61:928-934.

127. Taylor FB, Martin P, Thompson C, et al. Prazosin effects on objective sleep measures and clinical symptoms in civilian trauma posttraumatic stress disorder: a placebo-controlled study. Biol psychiatry. 2008; 63:629-32.

128. Raskind MA, Peskind ER, Kanter ED, et al. Reduction of nightmares and other PTSD symptoms in combat veterans by prazosin: a placebo-controlled study. Am J Psychiatry. 2003;160:371-373.

129. Taylor FB, Lowe K, Thompson C, et al. Daytime prazosin reduces psychological distress to trauma specific cues in civilian trauma posttraumatic stress disorder. Biol Psychiatry. 2006;59:577-581.

130. Peskind ER, Bonner LT, Hoff DJ, Raskind MA. Prazosin reduces trauma-related nightmares in older men with chronic posttraumatic stress disorder. J Geriatr Psychiatry Neurol. 2003;16:165-171.

131. Raskind MA, Thompson C, Petrie EC, et al. Prazosin reduces nightmares in combat veterans with posttraumatic stress disorder. J Clin Psychiatry. 2002;63:565-568.

132. Daly CM, Doyle ME, Radkind M, Raskind E, Daniels C. Clinical case series: the use of Prazosin for combat-related recurrent nightmares among Operation Iraqi Freedom combat veterans. Mil Med. 2005; 170:513-515.

133. Taylor F, Raskind MA. The alpha1-adrenergic antagonist prazosin improves sleep and nightmares in civilian trauma posttraumatic stress disorder. J Clin Psychopharmacol. 2002;22:82-85.

134. Ramey-Hartung B, El-Mallakh RS, Reynolds KK. Pharmacogenetic testing in schizophrenia and posttraumatic stress disorder. Clin Lab Med. 2008;28:627-643.

135. Heils A, Teufel A, Petri S, et al. Allelic variation of human serotonin transporter gene expression. J Neurochem. 1996;66:2621-2624.

136. Lesch KP, Bengel D, Heils A, et al. Association of anxiety-related traits with a polymorphism in the serotonin transporter gene regulatory region. Science. 1996;274:1527-1531.

Neuropsychiatric Disease and Treatment

\section{Publish your work in this journal}

Neuropsychiatric Disease and Treatment is an international, peerreviewed journal of clinical therapeutics and pharmacology focusing on concise rapid reporting of clinical or pre-clinical studies on a range of neuropsychiatric and neurological disorders. This journal is indexed on PubMed Central, the 'PsycINFO' database and CAS, and is the official
137. Bradley R, Greene J, Russ E, Dutra L, Westen D. A multidimensional meta-analysis of psychotherapy for PTSD. Am J Psychiatry. 2005; 162:214-227.

138. Philibert RA, Sandhu H, Hollenbeck N, Gunter T, Adams W, Madan A. The relationship of 5HTT (SLC6A4) methylation and genotype on mRNA expression and liability to major depression and alcohol dependence in subjects from the Iowa Adoption Studies. Am J Med Genet B Neuropsychiatr Genet. 2008;147B:543-549.

139. Kilpatrick DG, Koenen KC, Ruggiero KJ, et al. The serotonin transporter genotype and social support and moderation of posttraumatic stress disorder and depression in hurricane-exposed adults. Am J Psychiatry. 2007;164:1693-1699.

140. Norrholm SD, Ressler KJ. Genetics of anxiety and trauma-related disorders. Neurosci. 2009; 164(1):272-287. Epub 2009 Jun 18.

141. Koenen KC. Genetics of posttraumatic stress disorder: review and recommendations for future studies. J Traum Stress. 2007;20: 737-750.

142. Broekman BFP, Olff M, Boer F. The genetic background to TSD. Neurosci Biobehav Rev. 2007;31:348-362.

143. Charney DS. Psychobiological mechanisms of resilience and vulnerability: implications for successful adaptation to extreme stress. Am J Psychiatry. 2004;161:195-216.

144. Rasmusson AM, Vythilingam M, Morgan CA III. The neuroendocrinology of posttraumatic stress disorder: new directions. CNS Spectr. 2003;8:651-656, 665-667.

145. Rauch SL, Shin LM, Phelps EA. Neurocircuitry models of posttraumatic stress disorder and extinction: human neuroimaging research-past, present, and future. Biol Psychiatry. 2006;60:376-382.

146. Binder EB, Bradley RG, Liu W, et al. Association of FKBP5 polymorphisms and childhood abuse with risk of posttraumatic stress disorder symptoms in adults. JAMA. 2008;299:1291-1305.

147. Hubler TR, Scammell JG. Intronic hormone response elements mediate regulation of FKBP5 by progestins and glucocorticoids. Cell Stress Chaperones. 2004;9:243-252.

148. Newcomer JW, Krystal JH. NMDA receptor regulation of memory and behavior in humans. Hippocampus. 2001;11:529-542.

149. Morris RG, Davis S, Butcher SP. Hippocampal synaptic plasticity and NMDA receptors: a role in information storage? Philos Trans $R$ Soc London. 1990;329:187-204.

150. Castellano C, Cestari V, Ciamei A. NMDA receptors and learning and memory processes. Curr Drug Targets. 2001;2:273-283.

151. Bear MF. A synaptic basis for memory storage in the cerebral cortex. Proc Natl Acad Sci US A. 1996;93:13453-13459.

152. Walker DL, Ressler KJ, Lu KT, Davis M. Facilitation of conditioned fear extinction by systemic administration or intra-amygdala infusions of D-cycloserine as assessed with fear-potentiated startle in rats. J Neurosci. 2002;22:2343-2351.

153. Ledgerwood L, Richardson R, Cranney J. D-cycloserine and the facilitation of extinction of conditioned fear: consequences for reinstatement. Behav Neurosci. 2004;118:505-513.

154. Ressler KJ, Rothbaum BO, Tannenbaum L, et al. Cognitive enhancers as adjuncts to psychotherapy: use of D-cycloserine in phobic individuals to facilitate extinction of fear. Arch Gen Psychiatry. 2004;61:1136-1144.

155. Chhatwal JP, Davis M, Maguschak KA, Ressler KJ. Enhancing cannabinoid neurotransmission augments the extinction of conditioned fear. Neuropsychopharmacol. 2005;30:516-524.

journal of The International Neuropsychiatric Association (INA). The manuscript management system is completely online and includes a very quick and fair peer-review system, which is all easy to use. Visit http://www.dovepress.com/testimonials.php to read real quotes from published authors. 